Open Access

\title{
Prevalence of fatigue in patients 3 months after stroke and association with early motor activity: a prospective study comparing stroke patients with a matched general population cohort
}

Thorlene Egerton ${ }^{1 *}$, Anne Hokstad $^{1,2}$, Torunn Askim ${ }^{1,3}$, Julie Bernhardt ${ }^{4}$ and Bent Indredavik ${ }^{1,2}$

\begin{abstract}
Background: Fatigue is a common complaint after stroke. Reasons for higher prevalence are still unclear. This study aimed to determine if fatigue prevalence in stroke patients is different to that of age and gender matched general population controls, and to explore whether early motor activity was associated with reduced likelihood of fatigue three months after stroke.

Methods: This was a prospective multicenter cohort study of stroke patients admitted to eleven regional Norwegian hospitals, within 14 days after stroke. Stroke patients $(n=257)$ were age and gender matched to participants in a general population health survey (HUNT3-survey) carried out in a regional county of central Norway. The single-item fatigue questionnaire from the HUNT3-survey was administered to both groups to compare prevalence. The association between early motor activity (time in bed, time sitting out of bed, and time upright) and fatigue at three months after stroke (Fatigue Severity Scale) was tested with logistic regression. Simple models including each activity outcome, with adjustment for stroke severity and pre-stroke function, were tested, as well as a comprehensive model that included additional independent variables of depression, pain, pre-stroke fatigue, age and gender.

Results: Prevalence was higher after stroke compared with the general population: $31.1 \%$ versus $10.9 \%$. In the simple regression models, none of the early motor activity categories were associated with fatigue three months after stroke. In the comprehensive model, depression, pain and pre-stroke fatigue were significantly associated with post-stroke fatigue. Time in bed through the daytime during hospital stay approached statistical significance $(p=0.058)$ with an odds ratio for experiencing fatigue of $1.02(95 \% \mathrm{Cl} 1.00-1.04)$ for each additional 5.4 minutes in bed.

Conclusions: Stroke patients had higher prevalence of fatigue three months after stroke than the age and gender matched general population sample, which may be partly explained by the stroke population being in poorer health overall. The relationship between early motor activity (and inactivity) and fatigue remains unclear. Further research, which may help drive development of new treatments to target this challenging condition, is needed.
\end{abstract}

Keywords: Stroke, Fatigue, Physical activity, Early mobilization, HUNT

\footnotetext{
* Correspondence: thor@sutmap.com

Thorlene Egerton and Anne Hokstad are joint first authorship.

1 Department of Neuroscience, Faculty of Medicine, Norwegian University of

Science \& Technology, Trondheim, Norway

Full list of author information is available at the end of the article
} 


\section{Background}

Fatigue is described as a "constant weariness unrelated to previous exertion levels and not usually ameliorated by rest" [1]. Perceptions of fatigue are a common complaint among older people and for those with a range of chronic diseases including stroke. The prevalence of fatigue in the general population has been variably reported from 5 to $47 \%$, depending on the population studied, the questionnaire used, and the threshold score used to differentiate those with fatigue from those without [2-5]. Prevalence appears to increase with the number of chronic diseases $[6,7]$, and is higher in women [8], but findings are inconsistent for age $[3,9]$.

Prevalence is elevated even further following stroke, ranging from 35 to $92 \%$ [10], again depending on the tool used to measure fatigue, but also depending on the time since stroke and sample selection strategies [10-13]. Post-stroke fatigue (PSF) is distressing and debilitating. It is associated with higher levels of dependency $[14,15]$ and poorer quality of life [16]. It also independently predicts institutionalization and mortality after stroke $[17,18]$. Fatigue is rarely assessed in clinical practice and poorly managed, largely because strong evidence supporting effectiveness of fatigue-reducing interventions, either for fatigue in general, or for fatigue unique to stroke patients, is lacking.

Fatigue after stroke is complex, and while fatigue can be experienced secondary to medications, sleep disorders and/or medical complications [19], it is probable that PSF also relates to the brain injury itself $[14,17$, 20-22]. Ongoing fatigue may be compounded by reduced activity and subsequent deconditioning, particularly in the sub-acute phase, perhaps in combination with the increased energy cost of movement due to impairment [22-25]. Our current understanding of the biology of fatigue is limited. Understanding how PSF may differ from other fatigue is clinically important as unique management options may be required. If deconditioning and movement inefficiency play a crucial role in the experience of fatigue later after stroke, increased physical activity opportunities and movement training may be further endorsed as a treatment approach.

Several previous studies have investigated risk factors for PSF. Evidence suggests the main predictors for fatigue in the sub-acute phase are depression [11, 26], pre-stroke fatigue [26-28], and pain [29, 30]. Recent evidence suggests that activity early after stroke (step count at one month) predicts fatigue later after stroke (six and 12 months) [31]. However, knowledge is limited on the role of physical activity on fatigue levels for stroke patients, especially in the early phase after stroke.

Previous prevalence studies have often had restricted sample selection of stroke patients leading to subpopulation analyses, and not controlling for age and gender in comparison populations [32-34]. The present study firstly aimed to determine the prevalence among a less selective stroke population three months after stroke, and to directly compare prevalence with an age and gender matched general population sample from a similar region. We hypothesized that the fatigue prevalence would be higher in the stroke sample. The second aim of this study was to investigate the relationship between motor activity early after stroke and PSF. Because some evidence exists supporting the positive impact of physical activity on fatigue, we hypothesized that patients engaged in more motor activity early after stroke would have reduced likelihood of fatigue at three months, after adjustment for stroke severity and prestroke function, and independent of depression, pain, pre-stroke fatigue, age and gender. A reversed causal pathway was also considered possible as the reduced activity early after stroke may be caused by fatigue which then persists three months after stroke [13].

\section{Methods}

\section{Study design and settings}

This was a prospective observational study including patients admitted to eleven Norwegian hospitals [35]. An age and gender matched control group was derived from a population-based study in the county of Nord-Trøndelag [36], were two of the eleven hospitals were located.

\section{Study participants}

From 1st December 2011 to 11th June 2013, all consecutive acute first ever or recurrent stroke patients (except those with subarachnoid haemorrhages) admitted to the eleven stroke units were invited to participate, provided they were over 18 years of age, understood Norwegian and were not on palliative treatment. Stroke was defined according to the World Health Organisation definition. Recruitment was within 14 days after stroke onset. In keeping with Norwegian consent procedures, for patients unable to sign informed consent, verbal consent to participate was obtained from their next of kin. Further details of the study methods can be found in a prior publication [35]. Patients alive at three months, were contacted either in person or by telephone interview for assessment of perceptions of fatigue, depression, and pain.

Community-dwelling controls came from the NordTrøndelag population Health Survey3 (HUNT3-survey) [36]. The HUNT3-survey is a population-based study of the Norwegian county of Nord-Trøndelag. Two of the eleven hospitals in the stroke study were located in Nord-Trøndelag. Data were collected from October 2006 to June 2008. All adult residents aged $\geq 20$ years were invited to participate in the study. The HUNT3- 
survey included several priority public health issues, and questionnaires included fatigue [37, 38], as outlined below. Of 93,860 eligible adults, 50,807 (54.1\%) returned the questionnaire and written consent. Participation was highest among people $60-69$ years $(71 \%)$ decreasing to $18 \%$ in the oldest age group 90-96 years. There was a selection bias toward more healthy individuals and higher socioeconomic status [39].

\section{Ethics}

The Regional Committee for Medical and Health Research Ethics in Central Norway approved the study and storage of data on behalf of all participating hospitals and also the use of data from the HUNT3-survey (REC numbers 2011/1428 and 2012/675 respectively).

\section{Baseline assessment of stroke patients}

Baseline characteristics of the stroke participants measured at inclusion included age, gender, pre-stroke function measured by modified Rankin scale (mRS) [40], stroke severity measured using National Institutes of Health Stroke Scale (NIHSS) [41], stroke type by Oxford classification [42], co-morbidities and pre-stroke fatigue. Pre-stroke fatigue was estimated from the following two items: 'Did you experience fatigue before you had your stroke' (yes/no), and, 'If yes, how long did you experience fatigue' (less than a week, less than three months, 3-6 months and more than six months). Patients who reported fatigue lasting longer than three months before the stroke were classified as having pre-stroke fatigue [11].

For the early motor activity outcomes, participants were observed every 10th minute during a working day from 8.00 am to $5.00 \mathrm{pm}$ using the method of behavioural mapping. Motor activity was defined as the proportions of the daytime spent (i) in bed, (ii) sitting out of bed and (iii) upright. The procedure was reported in detail in a previous publication [43].

\section{Data extracted from the HUNT3-survey}

Age and gender were used to select the general population sample from HUNT3-survey participants and data collected from the matched participants included comorbidities and fatigue.

\section{Outcome measures}

Stroke patients were assessed three months after the stroke. Fatigue was measured in both samples (stroke and controls) using a simple fatigue questionnaire from the HUNT3-survey. This was a single question about weariness/fatigue: "Do you feel, for the most part, strong and fit or tired and worn out?". There were seven response categories which ranged from " $1=$ very fit and healthy" to " $7=$ very tired and worn out", with the middle option as neutral. Fatigue was defined as a score $\geq 5$.
In the stroke group, a second fatigue questionnaire, the Fatigue Severity Scale (FSS) was also administered. The 9-item FSS is the most commonly used scale to measure fatigue in stroke patients $[16,28,44]$. The shorter 7 -item version of the FSS, FSS-7, was shown to have better psychometric properties in patients with stroke than the original 9-item version [2]. The FSS-7 was therefore chosen for this study.

Pain was assessed by a simple question 'Did you experience new pain after stroke? (yes/no)'. Depression was assessed by Hospital Anxiety and Depression Scale (HADS) [45]. HADS is a self-report questionnaire which comprises two subscales HADS-anxiety and HADSdepression (HADS-D), each with seven items scored from zero to three. The scores are summed to give a total score for each subscale ranging from 0 to 21 .

\section{Data management and analysis}

Stroke patients were matched by age (up to a maximum of 2 years difference) and gender to respondents from the HUNT3-survey [36] who had all the outcome measures of interest to this study and no history of previous stroke. The HUNT participant of the same gender with the closest age (in 0.1 year increments) to each stroke participant was selected, with the matching procedure carried out blinded to any other outcome measure. The number of participants with available data determined the sample size for the study.

FSS scores from the 7-point Likert scale response options were averaged to yield a score from 1.0 to 7.0. Higher scores indicate higher fatigue levels. Most studies recommend a cut-off score of $\geq 4.0$ as indicative of fatigue $[33,46]$. The FSS-7 and HADS-D questionnaires were excluded if less than four items were answered. Up to three missing items were imputed with the average of the answered items.

Fatigue prevalence was examined in both groups using the HUNT3-survey questionnaire. The proportion of participants from each group reporting fatigue $\geq 5$ on this questionnaire was compared using the chi-square test. Fatigue prevalence among the stroke patients was also reported using the FSS-7 with cut off of $\geq 4.0$.

The association between early motor activity and PSF was tested using logistic regression models with fatigue dichotomised using FSS-7 score $\geq 4$.0. Proportion of daytime in bed, sitting out of bed and upright were each tested in separate simple models. Stroke severity (NIHSS score) and pre-stroke function (mRS) were included as covariates. A single comprehensive multivariable logistic regression model also including HADS-D score, pain, pre-stroke fatigue, age and gender as additional independent variables was also examined. In this model both time in bed and time upright were included but time sitting out of bed was excluded as it is co-dependent on the 
other two activity categories. This model was designed to determine whether early motor activity or inactivity were independently associated with fatigue at 3 months.

\section{Results}

Two hundred and fifty-seven stroke participants were age and gender matched to HUNT3-survey participants for the prevalence study, and 199 stroke participants had the outcome measures needed for inclusion in the regression models (Fig. 1). Four patients had missing items on the FSS-7 questionnaire (one had three items missing and three had one item missing) and had the missing data imputed. There was a mean of 4.2 (SD 2.8) days from admission to the stroke unit to the day of inclusion in the study and behavioural mapping. Table 1 shows the descriptive data and fatigue prevalence for the age-gender-matched cohort. Data were available in both groups for several comorbid diseases. These were hypertension, heart failure, myocardial infarct, lung disease (including asthma and
COPD), kidney disease, diabetes mellitus, cancer and connective tissue disease (including rheumatoid arthritis and spondylitis). Thirty-four percent of the HUNT3-survey cohort had none of these diseases, while only $16 \%$ of the stroke patients had none. Twenty-five percent of the stroke patients had three or more of the diseases, compared with only $11 \%$ in the general population. Most patients were classified as PACI (40\%) according to the Oxford Classification, with only $7 \%$ as TACI. Prevalence of fatigue ranged from 24 to $41 \%$ across the different classification groups using the HUNT3 survey fatigue question, and ranged from 35 to $44 \%$ using FSS-7.

Chi-square test indicated a significant difference in fatigue prevalence between the groups $(31.1 \%$ among stroke versus $10.9 \%$ among healthy controls, $p<0.001$ ). Odds of a stroke patient experiencing fatigue three months after stroke were 3.7 times the odds for the general population. The prevalence of fatigue was broadly similar if using the FSS-7 scale with a cut off of $\geq 4.0$ for

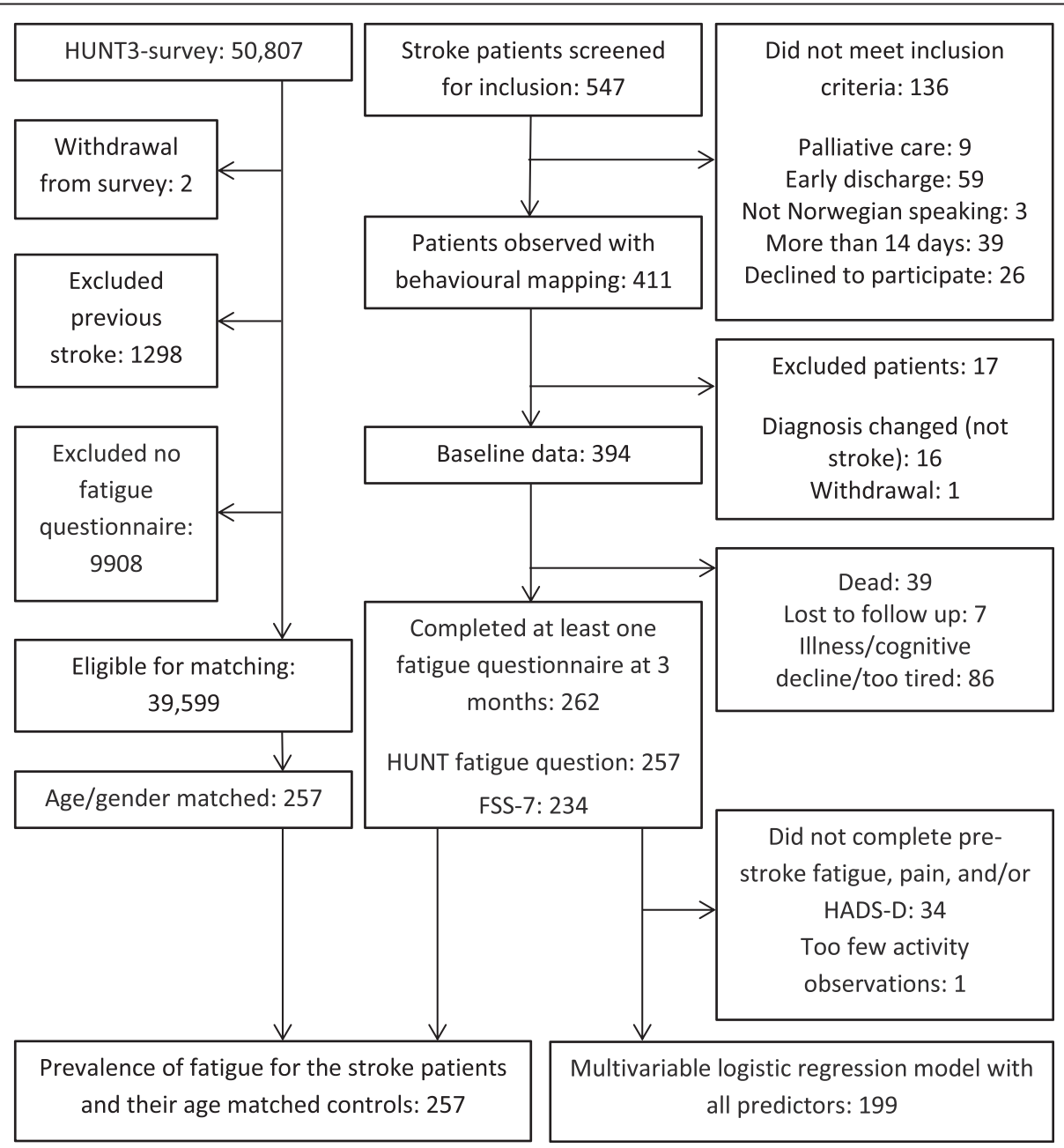

Fig. 1 Flow of participants through the study 
Table 1 Descriptive data and prevalence

\begin{tabular}{|c|c|c|c|c|}
\hline & & & Stroke & HUNT3-survey \\
\hline \multicolumn{3}{|l|}{ Gender, \% female } & $46.3 \%$ & $46.3 \%$ \\
\hline \multicolumn{3}{|l|}{ Age, mean (SD, range) } & $74.8(11.4,30.7-91.7)$ & $74.8(11.5,30.7-92.5)$ \\
\hline \multirow{7}{*}{$\begin{array}{l}\text { HUNT3 fatigue question (Do you feel, } \\
\text { for the most part, strong and fit or tired } \\
\text { and worn out?), n (\%) }\end{array}$} & \multicolumn{2}{|c|}{ 1. Very strong and fit } & $6(2.3 \%)$ & $11(4.3 \%)$ \\
\hline & \multicolumn{2}{|c|}{ 2. Strong and fit } & $29(11.3 \%)$ & $42(16.3 \%)$ \\
\hline & \multicolumn{2}{|c|}{ 3. Somewhat strong and fit } & $60(23.3 \%)$ & $88(34.2 \%)$ \\
\hline & \multicolumn{2}{|c|}{ 4. Somewhat in between } & $82(31.9 \%)$ & $88(34.2 \%)$ \\
\hline & \multicolumn{2}{|c|}{ 5. Somewhat tired and worn out } & $42(16.3 \%)$ & $21(8.2 \%)$ \\
\hline & \multicolumn{2}{|c|}{ 6. Tired and worn out } & $20(7.8 \%)$ & $6(2.3 \%)$ \\
\hline & \multicolumn{2}{|c|}{ 7. Very tired and worn out } & $18(7.0 \%)$ & $1(0.4 \%)$ \\
\hline \multicolumn{3}{|l|}{ Fatigue (HUNT3), \% score $\geq 5$} & $31.1 \%$ & $10.9 \%$ \\
\hline \multicolumn{3}{|l|}{ Fatigue (FSS-7), \% score $\geq 4.0$} & $34.6 \%$ & - \\
\hline \multirow[t]{4}{*}{ Early motor activity, mean (SD) } & \multicolumn{2}{|c|}{$\%$ of day in bed } & $36.6(23.4)$ & - \\
\hline & \multicolumn{2}{|c|}{$\%$ of day sitting out of bed } & $47.4(19.9)$ & - \\
\hline & \multicolumn{2}{|c|}{$\%$ of day upright } & $10.9(9.2)$ & - \\
\hline & \multicolumn{2}{|c|}{$\%$ of day not observed } & $5.1(7.9)$ & - \\
\hline \multicolumn{3}{|l|}{ Stroke severity (NIHSS), mean (SD) } & $5.0(5.0)$ & \\
\hline \multicolumn{3}{|l|}{ Function at inclusion (mRS), median, mean (SD) } & $3,3.2(1.1)$ & - \\
\hline \multicolumn{3}{|l|}{ Function at 3 months (mRS), median, mean (SD) } & $2,2.5(1.2)$ & - \\
\hline & & $\mathrm{n}$ (\% of cohort) & $\begin{array}{l}\% \text { reporting fatigue } \\
\text { with HUNT3, FSS-7 }\end{array}$ & \\
\hline \multirow[t]{5}{*}{ Oxford stroke classification groups } & $\mathrm{TACl}$ & 17 (7 \%) & $41 \%, 38 \%$ & - \\
\hline & $\mathrm{PACl}$ & $103(40 \%)$ & $34 \%, 40 \%$ & - \\
\hline & $\mathrm{LACl}$ & $58(23 \%)$ & $24 \%, 35 \%$ & - \\
\hline & $\mathrm{POCl}$ & $47(18 \%)$ & $30 \%, 44 \%$ & - \\
\hline & Haemorrhagic & $32(13 \%)$ & $31 \%, 35 \%$ & - \\
\hline \multirow[t]{8}{*}{ Co-morbidities, \% of cohort } & \multicolumn{2}{|l|}{ Hypertension } & $68 \%$ & $48 \%$ \\
\hline & \multicolumn{2}{|l|}{ Heart failure } & $10 \%$ & $7 \%$ \\
\hline & \multicolumn{2}{|c|}{ Myocardial infarct } & $19 \%$ & $14 \%$ \\
\hline & \multicolumn{2}{|c|}{ Lung disease (including asthma and COPD) } & $12 \%$ & $14 \%$ \\
\hline & \multicolumn{2}{|l|}{ Kidney disease } & $3 \%$ & $2 \%$ \\
\hline & \multicolumn{2}{|c|}{ Diabetes mellitus } & $15 \%$ & $11 \%$ \\
\hline & \multicolumn{2}{|l|}{ Cancer } & $18 \%$ & $9 \%$ \\
\hline & \multicolumn{2}{|c|}{$\begin{array}{l}\text { Connective tissue disease (including rheumatoid } \\
\text { arthritis and spondylitis }\end{array}$} & $8 \%$ & $8 \%$ \\
\hline
\end{tabular}

\footnotetext{
Descriptive data, prevalence of fatigue and early motor activity data are provided for the stroke patients $(n=257)$ and their age/gender-matched counterparts $(n=257)$ from HUNT3-Survey

FSS-7 7-item Fatigue Severity Scale, mRS modified Rankin Scale (range of scores 0-5), NIHSS National Institutes of Health Stroke Scale (range of scores 0-42), COPD chronic obstructive pulmonary disease
}

fatigue or using the HUNT3-survey fatigue question with cut off of $\geq 5$ ( 34.6 and $31.1 \%$ respectively).

The simple regression models testing the association of each of the early motor activity variables with fatigue (controlling for pre-stroke function and stroke severity) showed no association: proportion of time in bed OR $95 \%$ CI 0.99-1.02 ( $p=0.14)$, time sitting out of bed OR $95 \%$ CI 0.98-1.01 ( $p=0.21)$, and time upright OR $95 \%$ CI $0.96-1.03(p=0.58)$. In the comprehensive model, which included the independent variables in the simple models plus age, gender, pre-stroke fatigue, depression, and pain, only pre-stroke fatigue, depression and pain were significantly associated with fatigue at three months (Table 2). Proportion of time in bed approached significance $(p=0.058)$. If the point estimate for time in 
Table 2 Descriptive data and results of comprehensive multiple variable regression model

\begin{tabular}{|c|c|c|c|}
\hline Independent variables & & $B$ & OR (95 \% Cl) \\
\hline $\begin{array}{l}\text { Gender, } \\
\text { n (\%) female }\end{array}$ & 91 (45.7\%) & -0.58 & $0.56(0.26-1.21)$ \\
\hline $\begin{array}{l}\text { Age, mean } \\
\text { (SD, range) }\end{array}$ & $\begin{array}{l}73.8(11.7 \\
30.7-91.3)\end{array}$ & -0.002 & $1.00(0.97-1.03)$ \\
\hline $\begin{array}{l}\text { Pre-stroke fatigue, } \\
\text { n (\%) yes }\end{array}$ & $53(26.6 \%)$ & $1.30^{*}$ & $3.67(1.62-8.31)$ \\
\hline $\begin{array}{l}\text { Depression (HADS-D), } \\
\text { mean (SD) }\end{array}$ & $3.8(3.8)$ & $0.27^{*}$ & $1.31(1.17-1.47)$ \\
\hline $\begin{array}{l}\text { Pain (new since stroke), } \\
\text { n (\%) yes }\end{array}$ & 38 (19.1 \%) & $1.51^{*}$ & $4.55(1.82-11.34)$ \\
\hline $\begin{array}{l}\text { Pre-stroke function } \\
(\mathrm{mRS}), \text { mean (SD) }\end{array}$ & $1.4(1.1)$ & 0.04 & $1.04(0.70-1.54)$ \\
\hline $\begin{array}{l}\text { Stroke severity (NIHSS), } \\
\text { mean (SD) }\end{array}$ & $4.0(3.7)$ & 0.07 & $1.08(0.97-1.19)$ \\
\hline \multicolumn{4}{|l|}{ Early motor activity: } \\
\hline $\begin{array}{l}\% \text { of day in bed, } \\
\text { mean (SD) }\end{array}$ & $35.0(22.8)$ & $0.02^{*}$ & $1.02(1.00-1.04)$ \\
\hline $\begin{array}{l}\% \text { of day upright, } \\
\text { mean (SD) }\end{array}$ & $11.8(9.3)$ & 0.03 & $1.03(0.98-1.07)$ \\
\hline \multicolumn{4}{|c|}{$\begin{array}{l}N=199 \text {, dependent variable fatigue (FSS-7 score } \geq 4.0 \text { ), }{ }^{*} \text { significant at } p<0.05 \text {, } \\
{ }^{*} \text { significant at } p<0.10 \text { (trend). } 77 \text { participants }(38.7 \% \text { ) had fatigue } \\
\text { HADS-D Hospital Anxiety \& Depression Scale - Depression subscale (range of } \\
\text { scores } 0-21 \text { ), mRS modified Rankin Scale (range of scores 0-5), NIHSS National } \\
\text { Institutes of Health Stroke Scale (range of scores } 0-42 \text { ) }\end{array}$} \\
\hline
\end{tabular}

bed of $\mathrm{B}=0.02$ was correct, then for every additional $1 \%$ of the daytime (approximately $5.4 \mathrm{~min}$ ) spent in bed, there was $2 \%$ greater odds of experiencing fatigue at three months, holding all other variables constant.

Pre-stroke fatigue was one of the strongest independent predictors of PSF in our model (OR 3.7, $95 \%$ CI $1.6-8.3, p=0.002)$. The percentage of stroke patients that reported pre-stroke fatigue (had experienced fatigue prior to their stroke lasting at least three months) was $27 \%$, which was much higher than fatigue in the general population (11\%), although different measurement questionnaires were used. Of the 53 stroke participants reporting pre-stroke fatigue, 30 (57 \%), reported fatigue at three months. However, about a third (32 \%) of the 146 without pre-stroke fatigue reported fatigue three months after stroke.

\section{Discussion}

The main finding from the study was, a higher prevalence of fatigue in stroke patients even after careful matching with a general population sample. Prevalence of fatigue three months after stroke was around one third, using either FSS-7 with a cut off $\geq 4.0$, or using the HUNT3-survey questionnaire with a cut off $\geq 5$. The prevalence is lower than most previous studies where prevalence was most often reported in the range of $50 \%$. There are several possible reasons for this difference. Most obviously, use of different questionnaires and different cut-offs to define fatigue will affect prevalence findings. However, a further possible explanation may be the older patient population in our study compared with other studies. Younger patients may be more aware of fatigue due to increased likelihood of wanting to return to work, more social activities, and higher activity levels $[9,12,47]$. We did not find compelling support for our hypothesis that more early motor activity would be associated with decreased likelihood of PSF. Our analysis confirms previous findings that prestoke fatigue, depression and pain are important predictors. Time in bed almost reached statistical significance in the model, with $95 \% \mathrm{CI}$ for OR ranging from 1.00 (no association) to 1.04 (4\% greater odds of having fatigue for every 5.4 min of extra bed rest).

The stroke patients were about three times more likely to report fatigue than their community-living counterparts who had not experienced stroke. Our results also showed that the stroke patients had more than double the likelihood of having at least one other disease prior to their stroke compared to the general population, and more than double the likelihood of having three or more other diseases. This finding suggests that the higher prevalence of PSF may be at least in part related to the stroke population being in poorer health even before they had a stroke. The previous literature on the association between pre-stroke co-morbidities and fatigue is not clear. A study in young patients found an association between PSF and both diabetes mellitus and myocardial infarction [32], while two other studies found no such association [14, 15]. PSF is a serious problem which clearly warrants better monitoring and management. Our findings suggest that pre-stroke health is an important factor in development of PSF.

Our findings hint at the possibility that early inactivity may be associated with fatigue at three months. This may be similar to the finding that more time in bed, but not less time in higher level activities, was predictive of worse functional outcome three months after stroke [48]. Previous bed rest studies have shown bed rest in general is not a benign treatment, but harmful to health $[49,50]$. One possible mechanism by which bed rest could lead to higher levels of fatigue is the loss of cardiorespiratory fitness (CRF). CRF declines rapidly with bed rest [51], and is related to fatigue scores [52]. However, a recent review of cross-sectional studies found neither current physical activity levels nor CRF explained the level of fatigue experienced by people after stroke [53]. The risk of immobility-related complications increases with increased amounts of bed rest [54] suggesting that an association between fatigue and time in bed might also be explained by an increased prevalence of poststroke complications. The reverse causal pathway is also 
plausible, whereby early activity is dependent on the absence of fatigue. Despite our non-significant finding, we argue that further research is still needed to investigate how early fatigue and early inactivity are related to the problem of debilitating PSF.

A recent study found that patients with stroke, who had more effortful movement as determined by movement velocity during a timed hand movement task, were found to have increased likelihood of fatigue [22]. The authors proposed that the relationship could be due to either a simple effort-fatigue relationship or because both fatigue and reduced movement speed may result from an alteration in motor cortex excitability. With this finding in mind alongside our own results, PSF may be largely explained by a combination of poor pre-stroke health, effects of the brain injury (including early inflammatory effects), issues secondary to stroke during the acute phase (including medications, sleep problems and complications), depression, pain, the harmful consequences of too much inactivity, and increased effort of movement related to motor impairment.

Strengths of our study of PSF prevalence are the largely unselected stroke sample and the appropriate and well-matched control group. The main limitations of our study are that important confounding variables may be missing from the regression models such as cognitive function, medications and sleep disorders [19]. However, all models were adjusted for the most common and significant predicting variables after stroke. Secondly, there may be bias introduced because participants excluded due to lost to follow-up $(n=7)$, illness/cognitive decline/too tired $(n=86)$, or failure to complete pre-stroke fatigue, pain or depression questionnaires $(n=34)$ was potentially non-random. This group was likely to include the least healthy among the cohort. Thirdly, our measures of activity early after stroke may not adequately represent activity, or inactivity, of importance in preventing the development of PSF. All studies of PSF are limited by the multidimensional nature of fatigue and the inadequacies of the fatigue measurement tools used. Pre-stroke fatigue was measured with a different questionnaire to PSF, which may compromise our study, and early PSF was not measured. Finally, as the stroke units were all in Norway where national guidelines strongly recommend promotion of early out of bed activity, there may not have been sufficient between-individual spread of inactivity/activity levels for the role of early motor activity in predicting PSF to be revealed. The likelihood that the amount of bedrest is closely related to stroke severity and pre-stroke function also poses a challenge in this and future studies.
Carefully controlling for these confounders as in the present study, using pre-stroke mRS and NIHSS in the models, is helpful but may still be inadequate. These limitations may have resulted in the lack of support for our second hypothesis.

Some previous research supports there being a difference between mental and physical fatigue, particularly after stroke. The impact of a stroke (irrespective of whether ischemic or haemorrhagic) taxes the central nervous system and increases the level of cognitive strain, which may be interpreted as fatigue. Stroke patients may be physically capable of participating in rehabilitation exercises or physical activity, but feel unable to engage in the activity due a depletion of cognitive reserves or higher vascular burden. Global increases in allostatic load coupled with negative affect may further compound this problem. Drawing a distinction between mental and physical fatigue is currently difficult and controversial and was not attempted in our study. However, we suggest further research along these lines may yield important knowledge and facilitate management of the problem of PSF in the future.

PSF presents management challenges with few options currently available with proven effectiveness [55]. A combined cognitive therapy and graded exercise program has shown promise in alleviating fatigue, as well as cognitive therapy alone [56, 57]. However these trials are small and more research is needed on the effect of multifactorial approaches including exercise programs. It is apparent from the results of observational studies that improvement of general health and management of depression, sleep and pain should all help alleviate PSF. We also suggest that determining the appropriate amount of time spent on bed-rest versus out of bed activities early after stroke warrants urgent further investigation in relation to fatigue [31].

\section{Conclusions}

Despite the lower prevalence of PSF in this relatively unselected stroke population than typically previously reported, this study confirms a higher prevalence than in those without stroke and further highlights the problem of PSF. Pre-stroke health appears to be an important factor, as does post-stroke depression and pain. The role of early motor activity in the development of fatigue following stroke remains unclear.

\section{Abbreviations}

NIHSS: National Institutes of Health Stroke Scale; mRS: Modified Rankin Scale; FSS-7: Seven-item Fatigue Severity Scale; HADS-D: Hospital Anxiety \& Depression Scale - Depression subscale; OR: Odds ratio; Cl: Confidence interval.

\section{Competing interests}

The author(s) declare that they have no competing interests. 


\section{Authors' contributions}

$\mathrm{BI}$ and TA conceived the study. TE, AH, JB and TA designed the study and were involved in interpretation of the data. TE analysed the data and drafted the manuscript. AH participated in acquisition of data and data management. $\mathrm{BI}, \mathrm{JB}, \mathrm{AH}$, and TA were involved in critically revising the manuscript. All authors read and approved the final manuscript.

\section{Author information}

TE is a post-doctoral research fellow with the Geriatric, Movement and Stroke (GeMS) group, NTNU, with funding from Norwegian Women's Health Association and the Norwegian Extra Foundation for Health and Rehabilitation through EXTRA funds. AH is a PhD student with GeMS and a medical doctor. TA is a researcher with GeMS and an associate professor at the Department of Physiotherapy, Sør-Trøndelag University College. JB is a professor at Florey Institute of Neuroscience and Mental Health, Melbourne, Australia; and Bl is a professor at the Department of Neuroscience at NTNU and head of the Stroke Unit, Department of Medicine, St. Olavs University Hospital, Trondheim, Norway.

\section{Acknowledgments}

The authors wish to acknowledge Mari Gunnes, Christine Lundemo and Martina Reiten Bovim for their contribution data acquisition, and Jan Chamberlain and Li Chun Quang at the Florey Institute of Neuroscience and Mental Health for processing and preparing the behavioural mapping data for analysis.

The Nord-Trøndelag Health Study (The HUNT Study) is a collaboration between HUNT Research Centre (Faculty of Medicine, Norwegian University of Science and Technology), Nord-Trøndelag County Council, Central Norway Health Authority, and the Norwegian Institute of Public Health. The authors would also like to thank all the stroke patients and their families and the participating stroke units that agreed to take part in the study, as well as the HUNT study for contributing their data.

\section{Author details}

${ }^{1}$ Department of Neuroscience, Faculty of Medicine, Norwegian University of Science \& Technology, Trondheim, Norway. ${ }^{2}$ The Stroke Unit, Department of Medicine, St Olavs Hospital, University Hospital of Trondheim, Trondheim, Norway. ${ }^{3}$ Department of Physiotherapy, Faculty of Health Education and Social Work, Sør-Trøndelag University College, Trondheim, Norway. ${ }^{4}$ Florey Institute of Neuroscience and Mental Health, Melbourne, Australia.

Received: 7 July 2015 Accepted: 24 September 2015

Published online: 06 October 2015

\section{References}

1. De Groot MH, Phillips SJ, Eskes GA. Fatigue associated with stroke and other neurologic conditions: implications for stroke rehabilitation. Arch Phys Med Rehabil. 2003:84:1714-20.

2. Lerdal A, Wahl A, Rustoen T, Hanestad BR, Moum T. Fatigue in the general population: a translation and test of the psychometric properties of the Norwegian version of the fatigue severity scale. Scand J Public Health. 2005;33:123-30.

3. Loge JH, Ekeberg O, Kaasa S. Fatigue in the general Norwegian population: normative data and associations. J Psychosom Res. 1998;45:53-65.

4. Fukuda K, Dobbins JG, Wilson LJ, Dunn RA, Wilcox K, Smallwood D. An epidemiologic study of fatigue with relevance for the chronic fatigue syndrome. J Psychiatr Res. 1997;31:19-29.

5. Tennant KF, Takacs SE, Gau JT, Clark BC, Russ DW. A preliminary study of symptomatic fatigue in rural older adults. Aging Clin Exp Res. 2012;24:324-30

6. Gron KL, Ornbjerg LM, Hetland ML, Aslam F, Khan NA, Jacobs JW, et al. The association of fatigue, comorbidity burden, disease activity, disability and gross domestic product in patients with rheumatoid arthritis. Results from 34 countries participating in the Quest-RA program. Clin Exp Rheumatol. 2014;32:869-77.

7. Wright F, Hammer MJ, D'Eramo Melkus G. Associations between multiple chronic conditions and cancer-related fatigue: an integrative review. Oncol Nurs Forum. 2014;41:399-410.

8. Jason LA, Jordan KM, Richman JA, Rademaker AW, Huang CF, McCready W, et al. A community-based study of prolonged fatigue and chronic fatigue. J Health Psychol. 1999;4:9-26.
9. Dolan P, Kudrna L. More years, less yawns: fresh evidence on tiredness by age and other factors. J Gerontol B Psychol Sci Soc Sci. 2015;70:576-80.

10. Duncan F, Wu S, Mead GE. Frequency and natural history of fatigue after stroke: a systematic review of longitudinal studies. J Psychosom Res. 2012;73:18-27.

11. Lerdal A, Bakken LN, Rasmussen EF, Beiermann C, Ryen S, Pynten S, et al. Physical impairment, depressive symptoms and pre-stroke fatigue are related to fatigue in the acute phase after stroke. Disabil Rehabil. 2011;33:334-42.

12. Wang SS, Wang JJ, Wang PX, Chen R. Determinants of fatigue after first-ever ischemic stroke during acute phase. PLoS One. 2014;9.

13. van Eijsden HM, van de Port IG, Visser-Meily JM, Kwakkel G. Poststroke fatigue: who is at risk for an increase in fatigue? Stroke research and treatment. 2012.

14. Choi-Kwon S, Han SW, Kwon SU, Kim JS. Poststroke fatigue: characteristics and related factors. Cerebrovasc Dis. 2005;19:84-90.

15. Appelros P. Prevalence and predictors of pain and fatigue after stroke: $a$ population-based study. Int J Rehabil Res. 2006;29:329-33.

16. van de Port IG, Kwakkel G, Schepers VP, Heinemans $C T$, Lindeman E. Is fatigue an independent factor associated with activities of daily living, instrumental activities of daily living and health-related quality of life in chronic stroke? Cerebrovasc Dis. 2007;23:40-5.

17. Glader EL, Stegmayr B, Asplund K. Poststroke fatigue: a 2-year follow-up study of stroke patients in Sweden. Stroke. 2002;33:1327-33.

18. Hardy S, Studenski S. Fatigue predicts mortality among older adults. J Am Geritatr Soc. 2008;56:1910-4.

19. Kluger BM, Krupp LB, Enoka RM. Fatigue and fatigability in neurologic illnesses: proposal for a unified taxonomy. Neurology. 2013;80:409-16.

20. Christensen D, Johnsen SP, Watt T, Harder I, Kirkevold M, Andersen G. Dimensions of post-stroke fatigue: a two-year follow-up study. Cerebrovasc Dis. 2008;26:134-41.

21. Kuppuswamy A, Clark EV, Turner IF, Rothwell JC, Ward NS. Post-stroke fatigue: a deficit in corticomotor excitability? Brain. 2015;138:136-48.

22. Kuppuswamy A, Clark EV, Sandhu KS, Rothwell JC, Ward NS. Post-stroke fatigue: a problem of altered corticomotor control? J Neurol Neurosurg Psychiatry. 2015;86(8):902-4.

23. Michael KM, Allen JK, Macko RF. Fatigue after stroke: relationship to mobility, fitness, ambulatory activity, social support, and falls efficacy. Rehabil Nurs. 2006;31:210-7.

24. Mackay-Lyons MJ, Makrides L. Exercise capacity early after stroke. Arch Phys Med Rehabil. 2002;83:1697-702.

25. Stoquart G, Detrembleur C, Lejeune TM. The reasons why stroke patients expend so much energy to walk slowly. Gait Posture. 2012;36:409-13.

26. Chen YK, Qu JF, Xiao WM, Li WY, Weng HY, Li W, et al. Poststroke fatigue: risk factors and its effect on functional status and health-related quality of life. Int J Stroke. 2014.

27. Choi-Kwon S, Kim JS. Poststroke fatigue: an emerging, critical issue in stroke medicine. Int J Stroke. 2011;6:328-36.

28. Lerdal A, Bakken LN, Kouwenhoven SE, Pedersen G, Kirkevold M, Finset A, et al. Poststroke fatigue - a review. J Pain Symptom Manage. 2009;38:928-49.

29. Hoang CL, Salle JY, Mandigout S, Hamonet J, Macian-Montoro F, Daviet JC. Physical factors associated with fatigue after stroke: an exploratory study. Top Stroke Rehabil. 2012;19:369-76.

30. Naess H, Lunde L, Brogger J, Waje-Andreassen U. Fatigue among stroke patients on long-term follow-up. The Bergen stroke study. J Neurol Sci. 2012;312:138-41.

31. Duncan F, Lewis SJ, Greig CA, Dennis MS, Sharpe M, MacLullich AM, et al. Exploratory longitudinal cohort study of associations of fatigue after stroke. Stroke. 2015;46:1052-8.

32. Naess H, Nyland HI, Thomassen L, Aarseth J, Myhr KM. Fatigue at long-term follow-up in young adults with cerebral infarction. Cerebrovasc Dis. 2005;20:245-50.

33. Valko PO, Bassetti CL, Bloch KE, Held U, Baumann CR. Validation of the fatigue severity scale in a Swiss cohort. Sleep. 2008;31:1601-7.

34. Ponchel A, Bombois S, Bordet $\mathrm{R}$, Henon H. Factors associated with poststroke fatigue: a systematic review. Stroke Res Treatment. 2015;2015:347920

35. Hokstad A, Indredavik B, Bernhardt J, Ihle-Hansen H, Salvesen O, Seljeseth YM, et al. Hospital differences in motor activity early after stroke. A comparison of 11 Norwegian stroke units. J Stroke Cerebrovasc Dis. 2015. 
36. HUNT. The Health Study in Nord-Trøndelag (HUNT). Verdal:HUNT; Available at: www.ntnu.edu/hunt (accessed 8. May 2015).

37. Helvik AS, Engedal K, Krokstad S, Selbaek G. A comparison of life satisfaction in elderly medical inpatients and the elderly in a population-based study: Nord-Trondelag Health Study 3. Scandinavian J Public Health. 2011;39:337-44.

38. Krokstad S, Langhammer A, Hveem K, Holmen T, Midthjell K, Stene T, et al. Cohort profile: the HUNT study, Norway. Int J Epidemiol. 2013;42:968-77.

39. Langhammer A, Krokstad S, Romundstad P, Heggland J, Holmen J. The HUNT study: participation is associated with survival and depends on socioeconomic status, diseases and symptoms. BMC Med Res Methodol. 2012;12:143.

40. Banks JL, Marotta CA. Outcomes validity and reliability of the modified Rankin scale: implications for stroke clinical trials: a literature review and synthesis. Stroke. 2007;38:1091-6.

41. Brott T, Adams Jr HP, Olinger CP, Marler JR, Barsan WG, Biller J, et al. Measurements of acute cerebral infarction: a clinical examination scale. Stroke. 1989;20:864-70.

42. Bamford J, Sandercock P, Dennis M, Burn J, Warlow C. Classification and natural history of clinically identifiable subtypes of cerebral infarction. Lancet. 1991;337:1521-6.

43. Bernhardt J, Dewey H, Thrift A, Donnan G. Inactive and alone: physical activity within the first 14 days of acute stroke unit care. Stroke. 2004;35:1005-9.

44. Naess H, Waje-Andreassen U, Thomassen L, Nyland H, Myhr KM. Health-related quality of life among young adults with ischemic stroke on long-term follow-up. Stroke. 2006;37:1232-6.

45. Zigmond AS, Snaith RP. The hospital anxiety and depression scale. Acta Psychiatr Scand. 1983;67:361-70.

46. Krupp LB, LaRocca NG, Muir-Nash J, Steinberg AD. The fatigue severity scale. Application to patients with multiple sclerosis and systemic lupus erythematosus. Arch Neurol. 1989;46:1121-3.

47. Naess $\mathrm{H}$, Nyland $\mathrm{H}$. Poststroke fatigue and depression are related to mortality in young adults: a cohort study. BMJ Open. 2013;3.

48. Askim T, Bernhardt J, Salvesen O, Indredavik B. Physical activity early afte stroke and its association to functional outcome 3 months later. J Stroke Cerebrovasc Dis. 2014;23:e305-12

49. Thyfault JP, Booth FW. Lack of regular physical exercise or too much inactivity. Curr Opin Clin Nutr Metab Care. 2011:14:374-8.

50. Allen C, Glasziou P, Del Mar C. Bed rest: a potentially harmful treatment needing more careful evaluation. Lancet. 1999;354:1229-33.

51. Coker RH, Hays NP, Williams RH, Wolfe RR, Evans WJ. Bed rest promotes reductions in walking speed, functional parameters, and aerobic fitness in older, healthy adults. J Gerontol A Biol Sci Med Sci. 2015:70:91-6.

52. Egerton T, Chastin SFM, Stensvold D, Helbostad JL. Fatigue may contribute to reduced physical activity among older people: An observational study. J Gerontol A Biol Sci Med Sci 2015. In press.

53. Duncan F, Kutlubaev MA, Dennis MS, Greig C, Mead GE. Fatigue after stroke: a systematic review of associations with impaired physical fitness. Int J Stroke. 2012;7:157-62.

54. Govan L, Langhorne P, Weir CJ. Does the prevention of complications explain the survival benefit of organized inpatient (stroke unit) care?: further analysis of a systematic review. Stroke. 2007;38:2536-40.

55. Mead G, Bernhardt J, Kwakkel G. Stroke: physical fitness, exercise, and fatigue. Stroke Res Treatment. 2012;2012:632531.

56. Zedlitz AM, Rietveld TC, Geurts AC, Fasotti L. Cognitive and graded activity training can alleviate persistent fatigue after stroke: a randomized, controlled trial. Stroke. 2012;43:1046-51.

57. Clarke A, Barker-Collo SL, Feigin VL. Poststroke fatigue: does group education make a difference? A randomized pilot trial. Top Stroke Rehabil. 2012;19:32-9.

\section{Submit your next manuscript to BioMed Central and take full advantage of:}

- Convenient online submission

- Thorough peer review

- No space constraints or color figure charges

- Immediate publication on acceptance

- Inclusion in PubMed, CAS, Scopus and Google Scholar

- Research which is freely available for redistribution 